\title{
Epicardial Adipose Tissue Radiodensity Is Associated With All-cause Mortality in Patients Undergoing Hemodialysis
}

\section{Seong Soon Kwon}

Soonchunhyang University Seoul Hospital

Kyoungjin Choi

Soonchunhyang University Seoul Hospital

\section{Bo Da Nam}

Soonchunhyang University Seoul Hospital

\section{Haekyung Lee}

Soonchunhyang University Seoul Hospital

\section{Nam-Jun Cho}

Soonchunhyang University Cheonan Hospital

\section{Byoung Won Park}

Soonchunhyang University Seoul Hospital

\section{Hyoungnae Kim}

Soonchunhyang University Seoul Hospital

\section{Hyunjin Noh}

Soonchunhyang University Seoul Hospital

Jin Seok Jeon

Soonchunhyang University Seoul Hospital

\section{Dong Cheol Han}

Soonchunhyang University Seoul Hospital

\section{Sujeong Oh}

Soonchunhyang University Seoul Hospital

Soon Hyo Kwon ( $\sim$ ksoonhyo@schmc.ac.kr)

Soonchunhyang University Seoul Hospital

\section{Research Article}

Keywords: all-cause mortality, coronary computed tomography angiography, epicardial adipose tissue, EAT radiodensity, end-stage renal disease

Posted Date: August 6th, 2021 
DOI: https://doi.org/10.21203/rs.3.rs-783007/v1

License: (c) (1) This work is licensed under a Creative Commons Attribution 4.0 International License. Read Full License

Version of Record: A version of this preprint was published at Scientific Reports on November 29th, 2021. See the published version at https://doi.org/10.1038/s41598-021-02427-4. 


\section{Abstract}

The radiodensity and volume of epicardial adipose tissue (EAT) on computed tomography angiography (CTA) may provide information regarding cardiovascular risk and long-term outcomes. EAT volume is associated with mortality in patients undergoing incident hemodialysis. However, the relationship between EAT radiodensity/volume and all-cause mortality in patients with end-stage renal disease (ESRD) undergoing maintenance hemodialysis remains elusive. In this retrospective study, EAT radiodensity (in Hounsfield units) and volume (in $\mathrm{cm}^{3}$ ) on coronary CTA were quantified for patients with ESRD using automatic, quantitative measurement software between January 2012 and December 2018. All-cause mortality data (up to December 2019) were obtained from the Korean National Statistical Office. The prognostic values of EAT radiodensity and volume for predicting long-term mortality were assessed using multivariable Cox regression models, which were adjusted for potential confounders. A total of 221 patients (mean age: $64.88 \pm 11.09$ years; 114 women and 107 men) with ESRD were included. The median follow-up duration (interquartile range) after coronary CTA was 29.63 (range: 16.67-44.7) months. During follow-up, 82 (37.1\%) deaths occurred. In the multivariable analysis, EAT radiodensity (hazard ratio [HR]: 1.055; 95\% confidence interval [CI]: 1.015-1.095; $p=0.006$ ) was an independent predictor of all-cause mortality in patients with ESRD. However, EAT volume was not associated with mortality. Higher EAT radiodensity on CTA is associated with higher long-term all-cause mortality in patients undergoing prevalent hemodialysis, highlighting its potential as a prognostic imaging biomarker in patients undergoing hemodialysis.

\section{Introduction}

Epicardial adipose tissue (EAT) is located between the myocardial surface and the visceral layer of the pericardium. While EAT is known to exert a protective cardiovascular effect ${ }^{1}$, it has also been associated with cardiovascular disease and myocardial function ${ }^{2}$. Cross-sectional clinical and translational studies have suggested that EAT can contribute to the progression of coronary artery disease (CAD), heart failure, and atrial fibrillation ${ }^{3}$. EAT releases biochemical factors such as adiponectin, nitric oxide, and methylester prostacyclin, which can affect the myocardium and coronary vasculature through paracrine, vasocrine, or combined effects ${ }^{4}$. Expansion of EAT leads to increased peri-atrial fibrosis, while EAT inflammation can affect the coronary adventitia via the outside-to-inside pathway ${ }^{4}$. Therefore, assessments of EAT expansion (volume) and inflammation may provide prognostic information in patients with heart disease ${ }^{3}$. The volume or radiodensity of EAT can be non-invasively quantified and accurately measured by automatic quantitative measurement software using computed tomography (CT) images ${ }^{5}$. EAT radiodensity is reflected in terms of tissue attenuation and expressed as Hounsfield units (HU). Lipids are represented by negative $\mathrm{HU}$ values (from - 30 to $-190 \mathrm{HU}$ ) on CT, and inflammation can increase fat attenuation on CT by inhibiting adipogenesis in epicardial fat ${ }^{6}$.

Recent studies have reported that increased EAT thickness is associated with more profound cardiac hemodynamic derangements, such as greater elevation in cardiac filling pressure and more severe 
pulmonary hypertension ${ }^{7}$. Some evidence suggests that EAT plays an important role in cardiovascular risk assessment ${ }^{8,9}$ : A prospective study including asymptomatic patients reported that EAT volume and radiodensity measured using $\mathrm{CT}$ are associated with major adverse cardiac events ${ }^{10}$. In addition, EAT radiodensity has been associated with adverse cardiovascular events independent of EAT volume ${ }^{11}$. Changes in the radiodensity of fatty tissue on CT may represent changes in the composition of adipose tissue such as angiogenesis and inflammation ${ }^{12}$, which can in turn lead to adipose tissue remodeling and fibrosis ${ }^{13}$. As EAT radiodensity represents tissue inflammation and cardiovascular risk ${ }^{6}$, this parameter may have clinical relevance in patients with end-stage renal disease (ESRD), given that inflammation is highly prevalent and linked to cardiovascular disease in this population ${ }^{14}$. Moreover, sudden cardiac death is the largest contributor to mortality among patients with ESRD ${ }^{15}$, highlighting the need to identify a new biomarker for cardiovascular disease in the ESRD population.

Most previous studies regarding EAT included non-ESRD populations and did not investigate long-term outcomes such as all-cause mortality ${ }^{8,10}$. While some studies have reported that high EAT volume increases the risk of cardiovascular events in patients with reduced kidney function ${ }^{16}$ and predicts mortality among patients undergoing incident hemodialysis ${ }^{17}$, the relationship of EAT volume and radiodensity with long-term morality in the context of hemodialysis remains elusive. Therefore, the present study aimed to investigate whether EAT radiodensity and volume are related to all-cause mortality in patients undergoing hemodialysis.

\section{Results}

\section{Study population and clinical features}

A total of 2,122 coronary CTAs were performed during study period. We excluded 1,857 patients without ESRD. After an in-depth review of coronary CTA data, four patients were excluded due to poor image quality; finally, 221 patients with ESRD were included in the analysis (Fig. S1). Among them, 82 deaths (37.1\%) occurred during a median follow-up period of 29.63 months. Characteristics of the study population are presented in Table 1. The mean patient age was $64.88 \pm 11.09$ years, and 107 patients (48.42\%) were men. Most patients $(151,69 \%)$ were taking antiplatelet agents. There were 53 cases $(24 \%)$ of confirmed multi-vessel CAD following coronary CTA. After coronary CTA, 38 patients (17.19\%) underwent subsequent invasive coronary angiography as they required further evaluation. Among them, 29 and three patients underwent $\mathrm{PCl}$ and $\mathrm{CABG}$, respectively. 
Table 1

Baseline characteristics of patients with ESRD according to all-cause mortality.

\begin{tabular}{|c|c|c|c|c|}
\hline & Total $(n=221)$ & $\begin{array}{l}\text { Non-survival }(n= \\
82)\end{array}$ & Survival $(n=139)$ & $\begin{array}{l}p \\
\text { value }\end{array}$ \\
\hline Age (years) & $64.88 \pm 11.09$ & $68.88 \pm 9.68$ & $62.52 \pm 11.23$ & $\begin{array}{l}< \\
0.001\end{array}$ \\
\hline Male n, (\%) & 107 (48.42\%) & $41(50 \%)$ & $66(47.48 \%)$ & 0.824 \\
\hline BMI (kg/m2) & $\begin{array}{l}22.43(19.93 \\
25.04)\end{array}$ & $\begin{array}{l}22.35(19.9, \\
25.06)\end{array}$ & $\begin{array}{l}22.57(20.27, \\
24.87)\end{array}$ & 0.803 \\
\hline EAT volume $(\mathrm{mL})$ & $\begin{array}{l}126.83(84.75 \\
179.69)\end{array}$ & $\begin{array}{l}138.23(92.8 \\
203.13)\end{array}$ & $\begin{array}{l}124.34(80.4 \\
166.25)\end{array}$ & 0.169 \\
\hline EAT radiodensity (HU) & $-73.72 \pm 6.8$ & $-72.88 \pm 7.02$ & $-74.22 \pm 6.64$ & 0.165 \\
\hline $\begin{array}{l}\text { Hemodialysis duration, } \\
\text { years }\end{array}$ & $5(1.6,11.2)$ & $5.15(2.33,12)$ & $5(1.5,10.75)$ & 0.332 \\
\hline \multicolumn{5}{|l|}{ Cormorbidities } \\
\hline Diabetes & 105 (47.51\%) & $47(57.32 \%)$ & $58(41.73 \%)$ & 0.036 \\
\hline Smoking & $83(37.56 \%)$ & 35 (42.68\%) & $48(34.53 \%)$ & 0.287 \\
\hline $\begin{array}{l}\text { Previous } \mathrm{PCl} \text { or } \mathrm{CABG} \\
\text { state }\end{array}$ & 37 (16.74\%) & $22(26.83 \%)$ & 15 (10.79\%) & 0.004 \\
\hline Baseline LVEF (\%) & $60(48,66)$ & $57(45,65)$ & $61(50,67)$ & 0.029 \\
\hline \multicolumn{5}{|l|}{ Relevant medications } \\
\hline Antiplatelet agent & 151 (68.95\%) & $63(76.83 \%)$ & $88(64.23 \%)$ & 0.072 \\
\hline Aspirin & $48(21.92 \%)$ & $23(28.05 \%)$ & $25(18.25 \%)$ & \\
\hline P2Y12 inhibitor & $36(16.44 \%)$ & $10(12.2 \%)$ & $26(18.98 \%)$ & \\
\hline Cilostazol & $3(1.37 \%)$ & $2(2.44 \%)$ & $1(0.73 \%)$ & \\
\hline Dual antiplatelet & $64(29.22 \%)$ & $28(34.15 \%)$ & $36(26.28 \%)$ & \\
\hline Statin & $120(55.05 \%)$ & $46(56.1 \%)$ & $74(54.41 \%)$ & 0.919 \\
\hline Beta-blocker & $93(42.66 \%)$ & $39(47.56 \%)$ & $54(39.71 \%)$ & 0.320 \\
\hline ACE inhibitor or ARB & $91(41.74 \%)$ & $33(40.24 \%)$ & $58(42.65 \%)$ & 0.836 \\
\hline Phosphate binder & 169 (76.47\%) & 64 (78.05\%) & 105 (75.54\%) & 0.794 \\
\hline \multicolumn{5}{|c|}{$\begin{array}{l}\text { ACE, angiotensin converting enzyme; } A R B \text {, Angiotensin II receptor blocker; BMI, body mass index; } \\
\text { CABG, coronary artery bypass graft; CAD, coronary artery disease; CTA, CT angiography EAT, } \\
\text { epicardial adipose tissue; ESRD, end-stage renal disease; } H D L \text {, density lipoprotein; hs-CRP, high } \\
\text { sensitivity C-reactive protein; HU, hounsfield unit; } L D L \text {, low density lipoprotein; } L V E F \text {, left ventricular } \\
\text { ejection fraction; MI, myocardial infarction; PCl, percutaneous coronary intervention. }\end{array}$} \\
\hline
\end{tabular}




\begin{tabular}{|c|c|c|c|c|}
\hline & Total $(n=221)$ & $\begin{array}{l}\text { Non-survival }(n= \\
82)\end{array}$ & Survival $(n=139)$ & $\begin{array}{l}p \\
\text { value }\end{array}$ \\
\hline \multicolumn{5}{|l|}{ Laboratory data } \\
\hline Albumin (g/dL) & $3.94 \pm 0.52$ & $3.8(3.42,4.18)$ & $4(3.75,4.3)$ & 0.002 \\
\hline Total cholesterol (mg/dL) & $137(114.5,162.5)$ & $124(109,153)$ & $142.5(121,167)$ & 0.019 \\
\hline LDL cholesterol (mg/dL) & $77(56,98)$ & $70(53.5,92.5)$ & $\begin{array}{l}83.5(63.75 \\
101.25)\end{array}$ & 0.031 \\
\hline Hemoglobin (g/dL) & $10.46 \pm 1.58$ & $10.51 \pm 1.59$ & $10.43 \pm 1.58$ & 0.746 \\
\hline Calcium (mg/dL) & $9.1(8.5,9.6)$ & $9(8.4,9.6)$ & $9.2(8.6,9.65)$ & 0.113 \\
\hline Phosphorus (mg/dL) & $4.61 \pm 1.7$ & $4.43 \pm 1.81$ & $4.71 \pm 1.62$ & 0.250 \\
\hline Calcium x Phosphrus & $\begin{array}{l}40.67(29.76 \\
51.33)\end{array}$ & $\begin{array}{l}38.07(27.13 \\
50.91)\end{array}$ & $\begin{array}{l}41.85(33.74 \\
51.86)\end{array}$ & 0.076 \\
\hline hs-CRP (mg/dL) & $0.53(0.12,2.18)$ & $0.87(0.18,3.37)$ & $0.4(0.1,1.49)$ & 0.026 \\
\hline \multicolumn{5}{|l|}{ Result of coronary CTA } \\
\hline Multi-vessel CAD & $53(23.98 \%)$ & $23(28.05 \%)$ & $30(21.58 \%)$ & 0.355 \\
\hline Left main disease & $4(1.81 \%)$ & $2(2.44 \%)$ & $2(1.44 \%)$ & 0.629 \\
\hline Subsequent invasive CAG & $38(17.19 \%)$ & $18(21.95 \%)$ & $20(14.39 \%)$ & 0.544 \\
\hline Subsequent $\mathrm{PCl}$ & $29(13.12 \%)$ & $10(12.2 \%)$ & $19(13.67 \%)$ & 0.914 \\
\hline Subsequent $\mathrm{CABG}$ & $3(1.36 \%)$ & $1(1.22 \%)$ & $2(1.44 \%)$ & $>0.99$ \\
\hline $\begin{array}{l}\text { Duration of follow up } \\
\text { (months) }\end{array}$ & $29.63(16.67,44.7)$ & $15.98(7.9,33.02)$ & $\begin{array}{l}33.87(23.13 \\
50.48)\end{array}$ & $<.001$ \\
\hline \multicolumn{5}{|c|}{$\begin{array}{l}\text { ACE, angiotensin converting enzyme; } A R B \text {, Angiotensin II receptor blocker; BMI, body mass index; } \\
\text { CABG, coronary artery bypass graft; CAD, coronary artery disease; CTA, CT angiography EAT, } \\
\text { epicardial adipose tissue; ESRD, end-stage renal disease; HDL, density lipoprotein; hs-CRP, high } \\
\text { sensitivity C-reactive protein; HU, hounsfield unit; LDL, low density lipoprotein; LVEF, left ventricular } \\
\text { ejection fraction; MI, myocardial infarction; PCl, percutaneous coronary intervention. }\end{array}$} \\
\hline
\end{tabular}

\section{Comparison of survivor and non-survivor groups}

Non-survivors were older and had lower left ventricular ejection fraction and albumin levels than survivors. In addition, the frequency of diabetes, history of PCI or CABG, and increased high-sensitivity Creactive protein (hs-CRP) levels was greater among non-survivors than among survivors. However, there were no significant differences in serum calcium, phosphate, or calcium $\times$ phosphate levels between the two groups. Furthermore, there were no significant differences in the use of cardiovascular diseaserelated medications such as anti-platelet agents, statins, or phosphate binders between the two groups. 
The proportion of revascularizations $(\mathrm{PCl}$ or $\mathrm{CABG}$ ) performed after invasive coronary angiography was also similar in the two groups (Table 1).

\section{Relationship between EAT radiodensity/volume and other variables}

EAT radiodensity among the study population exhibited a normal distribution (Fig. S2). Among the variables expected to affect EAT radiodensity or volume, the change in EAT radiodensity exhibited a moderate negative correlation with EAT volume $(R=-0.5944)$ (Fig. S3) and body mass index $(B M I)(R=$ - 0.4521). EAT volume exhibited a moderate positive correlation with $B M I(R=0.5728)$. In the lipid profile, HDL cholesterol and triglyceride levels exhibited a slight negative correlation with EAT radiodensity (Table S1). The duration of dialysis was not correlated with EAT radiodensity or volume, and there were no differences in EAT radiodensity based on the presence or absence of diabetes mellitus ( $-73.98 \pm 6.59 \mathrm{HU}$ vs. $-73.49 \pm 7.00 \mathrm{HU} ; p=0.59$ ), or on the presence or absence of a history of coronary revascularization (PCl or $\mathrm{CABG})(-5.26 \pm 6.96$ vs. $-73.41 \pm 6.74 ; p=0.13)$. When comparing the three CAD categories, we observed no significant differences in EAT radiodensity between the groups (Fig. S4). EAT radiodensity was lower $(-74.75 \pm 7.16 \mathrm{HU}$ vs. $-72.41 \pm 6.13 \mathrm{HU} ; p=0.01)$ and volume was larger (155.48 $\pm 80.11 \mathrm{vs}$. $127.19 \pm 74.1, p=0.007)$ in statin-treated patients than in non-statin-treated patients.

\section{EAT radiodensity/volume in relation to mortality}

We conducted Cox proportional-hazards regression analysis to identify independent predictors of allcause mortality in patients with ESRD (Table 2). Fifteen variables were included in the analysis. After adjusting for confounding variables, the following were identified as significant independent predictors: (1) EAT radiodensity, (2) diabetes, (3) age, (4) duration of dialysis, and (5) hs-CRP level. Increased EAT radiodensity was associated with higher all-cause mortality in this analysis (HR: 1.055; 95\% Cl: 1.015$1.095 ; p=0.006$ ). However, EAT volume was not significantly associated with all-cause mortality in either the univariable or multivariable analysis. 
Table 2

Analysis of risk factors for long term all-cause mortality in patients with ESRD.

\begin{tabular}{|c|c|c|c|c|}
\hline \multirow[t]{2}{*}{ Variable } & \multicolumn{2}{|l|}{ Univariable analysis } & \multicolumn{2}{|c|}{ Multivariable analysis } \\
\hline & $\begin{array}{l}\text { Hazard Ratio (95\% } \\
\mathrm{Cl})\end{array}$ & $\begin{array}{l}p \\
\text { value }\end{array}$ & $\begin{array}{l}\text { Hazard Ratio (95\% } \\
\mathrm{Cl})\end{array}$ & $\begin{array}{l}p \\
\text { value }\end{array}$ \\
\hline Age & $\begin{array}{l}1.046(1.025- \\
1.067)\end{array}$ & $<.001$ & $\begin{array}{l}1.072(1.045- \\
1.100)\end{array}$ & $\dot{<} 001$ \\
\hline Male & $\begin{array}{l}1.206(0.782- \\
1.859)\end{array}$ & 0.398 & & \\
\hline Diabetes & $\begin{array}{l}1.729(1.114- \\
2.685)\end{array}$ & 0.015 & $\begin{array}{l}2.189(1.246- \\
3.845)\end{array}$ & 0.006 \\
\hline Smoking & $\begin{array}{l}1.363(0.880- \\
2.112)\end{array}$ & 0.166 & & \\
\hline $\begin{array}{l}\mathrm{PCl} \text { or } \mathrm{CABG} \text { (Previous or } \\
\text { subsequent) }\end{array}$ & $\begin{array}{l}1.611(1.033- \\
2.511)\end{array}$ & 0.035 & & \\
\hline Multi-vessel CAD on CT & $\begin{array}{l}1.162(0.718- \\
1.882)\end{array}$ & 0.541 & & \\
\hline Statin user & $\begin{array}{l}1.199(0.772- \\
1.863)\end{array}$ & 0.418 & & \\
\hline Duration of dialysis (years) & $\begin{array}{l}1.016(0.985- \\
1.049)\end{array}$ & 0.322 & $\begin{array}{l}1.044(1.005- \\
1.084)\end{array}$ & 0.028 \\
\hline Serum calcium $\mathrm{x}$ phosphorus & $\begin{array}{l}0.984(0.970- \\
0.998)\end{array}$ & 0.028 & & \\
\hline Serum albumin $(\mathrm{g} / \mathrm{dL})$ & $\begin{array}{l}0.574(0.374- \\
0.881)\end{array}$ & 0.011 & & \\
\hline Serum hemoglobin (g/dL) & $\begin{array}{l}1.043(0.909- \\
1.195)\end{array}$ & 0.551 & & \\
\hline Serum hs-CRP (mg/dL) & $\begin{array}{l}1.039(0.998- \\
1.082)\end{array}$ & 0.061 & $\begin{array}{l}1.043(1.002- \\
1.085)\end{array}$ & 0.040 \\
\hline LVEF (\%) & $\begin{array}{l}0.981(0.963- \\
0.998)\end{array}$ & 0.029 & & \\
\hline EAT volume & $\begin{array}{l}1.002(0.999- \\
1.005)\end{array}$ & 0.072 & & \\
\hline EAT radiodensity & $\begin{array}{l}1.026(0.994- \\
1.060)\end{array}$ & 0.111 & $\begin{array}{l}1.055(1.015- \\
1.095)\end{array}$ & 0.006 \\
\hline $\begin{array}{l}\text { BMI, body mass index; } \mathrm{CABG} \text {, c } \\
\text { computed tomography; EAT, ep } \\
\text { sensitivity C-reactive protein; } \mathrm{H} \\
\text { percutaneous coronary interve }\end{array}$ & $\begin{array}{l}\text { y artery bypass graft } \\
\text { l adipose tissue; ESF } \\
\text { isfield unit; LVEF, left }\end{array}$ & $\begin{array}{l}\text { AD, corc } \\
\text { end sta } \\
\text { ntricula }\end{array}$ & $\begin{array}{l}\text { ary artery disease; } \mathrm{CT} \\
\text { renal disease; } \mathrm{hs}-\mathrm{CR} \\
\text { jection fraction; } \mathrm{PCl} \text {, }\end{array}$ & igh \\
\hline
\end{tabular}


The optimum cutoff value of EAT radiodensity for predicting all-cause mortality derived from the receiver operating characteristic (ROC) curve analysis was $-73.28 \mathrm{HU}$. The probability of all-cause mortality in the ESRD population during the follow-up period is shown in Fig. 2 . The mortality rate was significantly higher in the high EAT radiodensity group $(>-73.28 \mathrm{HU})$ than in the low EAT radiodensity group $(62.53 \%$ vs. $46.78 \%$, log-rank $p=0.027$ ).

\section{Discussion}

In this study, we investigated the ability of differences in EAT volume and radiodensity to predict mortality in patients with ESRD undergoing hemodialysis. Our findings indicated that higher EAT radiodensity was associated with a poorer prognosis after adjustment for confounding factors. However, EAT volume did not predict long-term mortality in patients undergoing prevalent hemodialysis. These findings support the notion that EAT has active biologic properties and suggest a potential role of EAT radiodensity as a biomarker for patients with ESRD.

EAT radiodensity is advantageous as a biomarker, as it is relatively simple to measure when compared with perivascular or pericoronary fat volume/density. Moreover, as EAT can be quantified from noncontrast $\mathrm{CT}{ }^{10}$, there is no risk associated with exposure to contrast medium, which is especially critical for patients with chronic kidney disease. These benefits make determining EAT radiodensity a useful strategy for identifying high-risk patients with ESRD or renal insufficiency. Further studies involving larger cohorts of patients with ESRD are required to validate the applicability of EAT radiodensity on noncontrast CT.

Analyzing CTA imaging sequences may help to elucidate the biological effects of vascular inflammation such as expression of adipogenic genes, average adipocyte size, and lipid accumulation in pericoronary adipose tissue ${ }^{6}$. These findings suggest that high radiodensity in perivascular fat reflects prominent tissue inflammation. Considerable evidence suggests that EAT is closely related to coronary atherosclerosis 10,18-20; however, in our study, the severity of CAD was not correlated with EAT radiodensity. As reported in another study ${ }^{21}$, it is possible that the degree of CAD was not accurately assessed due to the high calcium burden in patients with ESRD. Indeed, another study reported that calcium blooming artifacts are a major concern when assessing the degree of coronary artery stenosis ${ }^{22}$.

However, EAT radiodensity may reflect myocardial states other than coronary artery atherosclerosis. Many studies have reported that EAT abnormalities are associated with atrial fibrillation ${ }^{3,23,24}$, while another has noted that arrhythmogenic mechanisms may include adipocyte infiltration into the heart ${ }^{25}$. Given that sudden cardiac death is the leading cause of mortality among patients with ESRD ${ }^{15}$, additional studies are required to determine whether EAT radiodensity and fatal arrhythmias (e.g., ventricular tachycardia/fibrillation) are related.

It is well known that chronic inflammation is highly prevalent among patients with ESRD due to uremiainduced nutritional and catabolic alterations ${ }^{26}$, and the presence of inflammation has been associated 
with increased mortality risk in these patients ${ }^{27}$. Another study reported that inflammation, as determined based on higher CRP and interleukin (IL)- 6 levels, was associated with a higher risk of sudden cardiac death among patients with ESRD ${ }^{28}$. Our results are consistent with those of a previous study ${ }^{29}$ in which the authors reported a significant association between CRP levels and mortality; however, EAT radiodensity was not associated with $\mathrm{CRP}$ levels. Therefore, we presumed that EAT radiodensity reflects a more heart-specific inflammatory state rather than systemic inflammation, and that this inflammatory response in the heart may contribute to mortality in patients with ESRD. As there is no fascia or other separating tissue, adipocytes in the epicardium may directly affect the myocardium, exacerbating myocardial lipotoxicity ${ }^{30}$. Myocardial lipotoxicity and extra-cardiac adiposity result in increased heart weight and decreased systolic function ${ }^{31}$, left ventricular hypertrophy, electrocardiographic abnormalities, and increased arrhythmogenicity ${ }^{32}$. We believe that chronic myocardial inflammatory conditions also influence EAT and contribute to mortality in patients with ESRD.

Our findings indicate that, unlike EAT radiodensity, EAT volume is not associated with all-cause mortality in patients undergoing maintenance hemodialysis. A previous study reported that high EAT volume predicts mortality in patients undergoing incident hemodialysis ${ }^{17}$. The difference in results is likely due to differences between the study populations. Previous studies have indicated that phosphate binders can increase EAT volume in patients undergoing hemodialysis ${ }^{33}$ and that high-phosphate treatments can also affect EAT volume in these patients. Therefore, we presumed that qualitative assessments of EAT based on inflammatory cell deposits and fibrosis are superior to quantitative assessments of EAT such as volume in terms of predicting prognosis in patients with ESRD.

Our study is subject to limitations. First, our analysis was limited by a relatively small sample size, ultimately restricting its statistical power. Nevertheless, the longitudinal analysis of mortality was a strength; hence, conclusions regarding causality can be confidently made. Second, we were unable to assess CVD related outcomes in this study. However, several studies have reported the major cause of death in ESRD is CVD ${ }^{15,34}$. Third, despite coronary calcium score being an important predictor of cardiac events, we were unable to assess the extent of coronary calcification due to the CTA protocol of our institution and retrospective study design. Last, we were only able to hypothesize about the pathophysiological relationship between CT-derived EAT radiodensity and all-cause mortality, which needs to be evaluated in dedicated large-scale studies.

In conclusion, Higher EAT radiodensity assessed by coronary CTA was associated with higher long-term all-cause mortality in patients with ESRD. Due to ease of measurement, EAT radiodensity may provide a useful method to noninvasively assess mortality risk in patients undergoing prevalent hemodialysis. Therefore, EAT radiodensity is a promising prognostic imaging biomarker in patients with ESRD.

\section{Methods}

\section{Study population}


This retrospective study was performed at a tertiary medical center. Between January 2012 and December 2018, a total of 2,122 consecutive patients underwent coronary CT angiography (CTA) at our institution due to clinical indications such as chest discomfort or dyspnea. Among these patients, patients with ESRD were identified based on a review of medical records. This study was carried out in accordance with the ethical principles of the Declaration of Helsinki and was approved by the Institutional Review Board of Soonchunhyang University Hospital (IRB no. 2019-04-032), which waived the requirement for informed consent due to the retrospective nature of the study.

\section{Variables and definitions}

Risk factors and clinical diagnoses for the included patients at the time of coronary CTA were acquired from the electronic medical record system of our institution. Laboratory variables, such as serum lipid profile and hemoglobin level, were also collected. History of percutaneous coronary intervention (PCI) or coronary artery bypass grafting (CABG) was assessed based on a review of the medical records and the results of coronary CTA. Left ventricular ejection fraction was evaluated via echocardiography (modified Simpson's method). The coronary CTA results were analyzed to identify multi-vessel CAD and left-main (LM) disease, which can also influence mortality. Multi-vessel CAD was defined as more than two major epicardial arteries with $>50 \%$ stenosis, while LM disease was defined as LM coronary stenosis $>50 \%$. The severity of CAD was categorized as follows: normal or mild CAD, one-vessel CAD (one major epicardial artery having $>50 \%$ stenosis ${ }^{35}$ ), and multi-vessel CAD. In select patients, invasive coronary angiography was performed after coronary CTA. The revascularization strategy after invasive coronary angiography (PCl or $\mathrm{CABG}$ ) was also analyzed.

\section{Coronary CTA and fat quantification}

All patients underwent CTA using two types of 128-slice multi-detector CT scanners (SOMATOM Definition Edge, Siemens Medical Solutions, Erlangen, Germany; and Discovery CT750 HD, GE Healthcare, Milwaukee, WI, USA). CT was performed using the following parameters: collimation, $0.6 \mathrm{~mm}$; slice acquisition, $2 \times 64$ (or 128) x $0.6 \mathrm{~mm}$ by means of $x$-flying focal spot; pitch, 0.2 ; tube voltage, $100-120 \mathrm{kV}$; gantry rotation time, $330 \mathrm{~ms}$. Patients received an $80-\mathrm{mL}$ bolus of contrast medium. All coronary CTA datasets were acquired using retrospective electrocardiographic gating and were automatically selected to allow synchrony with the heartbeat to enable efficient adaptive multi-segment image reconstruction.

CTA data were transferred to a post-processing workstation (syngo.via, Siemens) for further analysis by an investigator with 9 years of experience in cardiothoracic CT imaging. A dedicated semi-automatic software prototype (Cardiac Risk Assessment 1.2.1 syngo.via FRONTIER, Siemens AG, Healthcare Sector, Forchheim, Germany) was used for quantitative fat analysis. The EAT depot was defined as the fat tissue between the outer wall of the myocardium and the visceral layer of the pericardium. The software semiautomatically reconstructed the pericardium into a three-dimensional region of interest. Within this region, delineated by the pericardium, contiguous voxels between the limits of $-190 \mathrm{HU}$ and $-30 \mathrm{HU}$ were defined as adipose tissue. Radiodensity (mean and standard deviation with histogram) and volume were estimated across the total EAT (Fig. 1). To adjust for the attenuation difference between scans performed 
at different tube voltages, the radiodensity for scans performed at $100 \mathrm{kVp}$ was corrected by dividing by a conversion factor of 1.11485 to ensure that they could be compared to scans performed at $120 \mathrm{kVp}{ }^{12,36}$.

\section{Outcome}

The main outcome of the present study was all-cause mortality. Mortality data were obtained from the Korean National Statistical Office (Microdata Integrated Service, on-demand, 20,180,619, https://mdis.kostat.go.kr), as it is mandatory to report the death of any Korean national to the National Statistical Office. The data included deaths among study participants occurring before December 31, 2019. Data regarding the cause of death were not used in further analyses, as the cause of death did not depend on an accurate medical assessment.

\section{Data analysis}

Categorical variables are presented as numbers and percentages and were analyzed using chi-square or Fisher's exact tests. Continuous variables with normal distributions are expressed as the mean \pm standard deviation and were analyzed using independent Samples $t$-tests. Continuous variables without normal distributions were confirmed using the Shapiro-Wilk test, presented as the median (interquartile range), and analyzed using the Mann-Whitney U-test. When EAT radiodensity was analyzed according to the degree of CAD, statistical comparisons of individual groups were based on a one-way analysis of variance (ANOVA). Pearson's correlation coefficients were calculated to determine the relationships between EAT radiodensity and other continuous variables.

All-cause mortality according to the degree of EAT radiodensity was analyzed using the Kaplan-Meier method and log-rank tests. In addition, multivariable stepwise Cox proportional-hazards regression analysis was used to identify independent predictors of all-cause mortality. Factors used in the multivariable analysis included those with $p$ values $<.10$ in the univariable analysis as well as variables with known prognostic values. $p<.05$ was considered significant. All statistical analyses were performed using R version 3.6.1 and Rex version 3.0.3 (RexSoft Inc., Seoul, Korea).

\section{Declarations}

\section{Data availability}

The data underlying this article cannot be shared publicly to protect the privacy of individuals that participated in the study. The data will be shared on reasonable request to the corresponding author.

\section{Statement of Ethics}

\section{Competing interest}

The authors have no conflicts of interest to declare. 


\section{Acknowledgements}

This research was partly supported by the Bio \& Medical Technology Development Program of the National Research Foundation of Korea (NRF) funded by the Korean government (MSIT)(NRF2019M3E5D3073102), and the Soonchunhyang University research fund.

\section{Authors Contributions}

S.H.K. conceived of the idea for the manuscript and designed the study. S.S.K. and K.C. took the lead in writing the manuscript, analyzing data. BDN conceived of the idea and analyzed the coronary CTA. S.O. analyzed the coronary CTA, B.W.P., H.L., N.J.C., H.K., H.N., J.S.J, and D.C.H. reviewed the manuscript. All authors reviewed and discussed the results, and suggested additional analyses. All authors reviewed and contributed to the final manuscript.

\section{References}

1. Prati, F. et al. Eccentric atherosclerotic plaques with positive remodelling have a pericardial distribution: a permissive role of epicardial fat? A three-dimensional intravascular ultrasound study of left anterior descending artery lesions. Eur Heart J 24, 329-336, doi:10.1016/s0195668x(02)00426-8 (2003).

2. Baker, A. R. et al. Epicardial adipose tissue as a source of nuclear factor-kappaB and c-Jun Nterminal kinase mediated inflammation in patients with coronary artery disease. J Clin Endocrinol Metab 94, 261-267, doi:10.1210/jc.2007-2579 (2009).

3. Le Jemtel, T. H., Samson, R., Ayinapudi, K., Singh, T. \& Oparil, S. Epicardial Adipose Tissue and Cardiovascular Disease. Curr Hypertens Rep 21, 36, doi:10.1007/s11906-019-0939-6 (2019).

4. Cherian, S., Lopaschuk, G. D. \& Carvalho, E. Cellular cross-talk between epicardial adipose tissue and myocardium in relation to the pathogenesis of cardiovascular disease. Am J Physiol Endocrinol Metab 303, E937-949, doi:10.1152/ajpendo.00061.2012 (2012).

5. Hell, M. M. et al. Epicardial adipose tissue volume but not density is an independent predictor for myocardial ischemia. J Cardiovasc Comput Tomogr 10, 141-149, doi:10.1016/j.jcct.2016.01.009 (2016).

6. Antonopoulos, A. S. et al. Detecting human coronary inflammation by imaging perivascular fat. Sci Trans/ Med 9, doi:10.1126/scitransImed.aal2658 (2017).

7. Koepp, K. E., Obokata, M., Reddy, Y. N. V., Olson, T. P. \& Borlaug, B. A. Hemodynamic and Functional Impact of Epicardial Adipose Tissue in Heart Failure With Preserved Ejection Fraction. JACC Heart Fail 8, 657-666, doi:10.1016/j.jchf.2020.04.016 (2020).

8. Mahabadi, A. A. et al. Cardiac computed tomography-derived epicardial fat volume and attenuation independently distinguish patients with and without myocardial infarction. PLoS One 12, e0183514 doi:10.1371/journal.pone.0183514 (2017). 
9. Mahabadi, A. A. et al. Association of epicardial fat with cardiovascular risk factors and incident myocardial infarction in the general population: the Heinz Nixdorf Recall Study. J Am Coll Cardio/ 61, 1388-1395, doi:10.1016/j.jacc.2012.11.062 (2013).

10. Goeller, M. et al. Epicardial adipose tissue density and volume are related to subclinical atherosclerosis, inflammation and major adverse cardiac events in asymptomatic subjects. $J$ Cardiovasc Comput Tomogr 12, 67-73, doi:10.1016/j.jcct.2017.11.007 (2018).

11. Franssens, B. T., Nathoe, H. M., Leiner, T., van der Graaf, Y. \& Visseren, F. L. Relation between cardiovascular disease risk factors and epicardial adipose tissue density on cardiac computed tomography in patients at high risk of cardiovascular events. Eur J Prev Cardio/ 24, 660-670, doi:10.1177/2047487316679524 (2017).

12. Oikonomou, E. K. et al. Non-invasive detection of coronary inflammation using computed tomography and prediction of residual cardiovascular risk (the CRISP CT study): a post-hoc analysis of prospective outcome data. Lancet 392, 929-939, doi:10.1016/s0140-6736(18)31114-0 (2018).

13. Crewe, C., An, Y. A. \& Scherer, P. E. The ominous triad of adipose tissue dysfunction: inflammation, fibrosis, and impaired angiogenesis. J Clin Invest 127, 74-82, doi:10.1172/jci88883 (2017).

14. Krane, V. \& Wanner, C. Statins, inflammation and kidney disease. Nat Rev Nephro/7, 385-397, doi:10.1038/nrneph.2011.62 (2011).

15. Makar, M. S. \& Pun, P. H. Sudden Cardiac Death Among Hemodialysis Patients. Am J Kidney Dis 69, 684-695, doi:10.1053/j.ajkd.2016.12.006 (2017).

16. Cordeiro, A. C. et al. Epicardial fat accumulation, cardiometabolic profile and cardiovascular events in patients with stages 3-5 chronic kidney disease. J Intern Med 278, 77-87, doi:10.1111/joim.12344 (2015).

17. D'Marco, L. G. et al. Epicardial adipose tissue predicts mortality in incident hemodialysis patients: a substudy of the Renagel in New Dialysis trial. Nephrol Dial Transplant 28, 2586-2595, doi:10.1093/ndt/gft264 (2013).

18. Nakanishi, R. et al. Increase in epicardial fat volume is associated with greater coronary artery calcification progression in subjects at intermediate risk by coronary calcium score: a serial study using non-contrast cardiac CT. Atherosclerosis 218, 363-368, doi:10.1016/j.atherosclerosis.2011.07.093 (2011).

19. Bettencourt, N. et al. Epicardial adipose tissue is an independent predictor of coronary atherosclerotic burden. Int J Cardio/ 158, 26-32, doi:10.1016/j.jicard.2010.12.085 (2012).

20. Liu, Z. et al. Association of epicardial adipose tissue attenuation with coronary atherosclerosis in

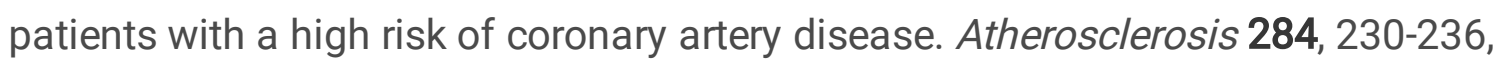
doi:10.1016/j.atherosclerosis.2019.01.033 (2019).

21. Hakeem, A., Bhatti, S. \& Chang, S. M. Screening and risk stratification of coronary artery disease in end-stage renal disease. JACC Cardiovasc Imaging 7, 715-728, doi:10.1016/j.jcmg.2013.12.015 (2014). 
22. Kalisz, K. et al. Artifacts at Cardiac CT: Physics and Solutions. Radiographics 36, 2064-2083, doi:10.1148/rg.2016160079 (2016).

23. Wong, C. X., Ganesan, A. N. \& Selvanayagam, J. B. Epicardial fat and atrial fibrillation: current evidence, potential mechanisms, clinical implications, and future directions. Eur Heart J 38, 12941302, doi:10.1093/eurheartj/ehw045 (2017).

24. Nakamori, S., Nezafat, M., Ngo, L. H., Manning, W. J. \& Nezafat, R. Left Atrial Epicardial Fat Volume Is Associated With Atrial Fibrillation: A Prospective Cardiovascular Magnetic Resonance 3D Dixon Study. J Am Heart Assoc 7, doi:10.1161/jaha.117.008232 (2018).

25. Mahajan, R. et al. Electrophysiological, Electroanatomical, and Structural Remodeling of the Atria as Consequences of Sustained Obesity. J Am Coll Cardiol 66, 1-11, doi:10.1016/j.jacc.2015.04.058 (2015).

26. Cobo, G., Lindholm, B. \& Stenvinkel, P. Chronic inflammation in end-stage renal disease and dialysis. Nephrol Dial Transplant 33, iii35-iii40, doi:10.1093/ndt/gfy175 (2018).

27. Jofré, R., Rodriguez-Benitez, P., López-Gómez, J. M. \& Pérez-Garcia, R. Inflammatory syndrome in patients on hemodialysis. J Am Soc Nephrol 17, S274-280, doi:10.1681/asn.2006080926 (2006).

28. Parekh, R. S. et al. The association of sudden cardiac death with inflammation and other traditional risk factors. Kidney Int 74, 1335-1342, doi:10.1038/ki.2008.449 (2008).

29. Bazeley, J. et al. C-reactive protein and prediction of 1-year mortality in prevalent hemodialysis patients. Clin J Am Soc Nephrol 6, 2452-2461, doi:10.2215/cjn.00710111 (2011).

30. Nagy, E., Jermendy, A. L., Merkely, B. \& Maurovich-Horvat, P. Clinical importance of epicardial adipose tissue. Arch Med Sci 13, 864-874, doi:10.5114/aoms.2016.63259 (2017).

31. lacobellis, G. \& Sharma, A. M. Adiposity of the heart. Ann Intern Med 145, 554-555; author reply 555, doi:10.7326/0003-4819-145-7-200610030-00021 (2006).

32. Poirier, P. et al. Obesity and cardiovascular disease: pathophysiology, evaluation, and effect of weight loss. Arterioscler Thromb Vasc Bio/ 26, 968-976, doi:10.1161/01.ATV.0000216787.85457.f3 (2006).

33. Ko, S. M. et al. Epicardial adipose tissue volume increase in hemodialysis patients treated with sevelamer or calcium-based phosphate binders: a substudy of the Renagel in new dialysis trial. $J$ Nephrol 29, 683-690, doi:10.1007/s40620-016-0310-9 (2016).

34. Thompson, S. et al. Cause of Death in Patients with Reduced Kidney Function. J Am Soc Nephro/26, 2504-2511, doi:10.1681/asn.2014070714 (2015).

35. Min, J. K. et al. Prognostic value of multidetector coronary computed tomographic angiography for prediction of all-cause mortality. J Am Coll Cardio/ 50, 1161-1170, doi:10.1016/j.jacc.2007.03.067 (2007).

36. Okayama, S. et al. The influence of effective energy on computed tomography number depends on tissue characteristics in monoenergetic cardiac imaging. Radiol Res Pract 2012, 150980, doi:10.1155/2012/150980 (2012). 


\section{Figures}

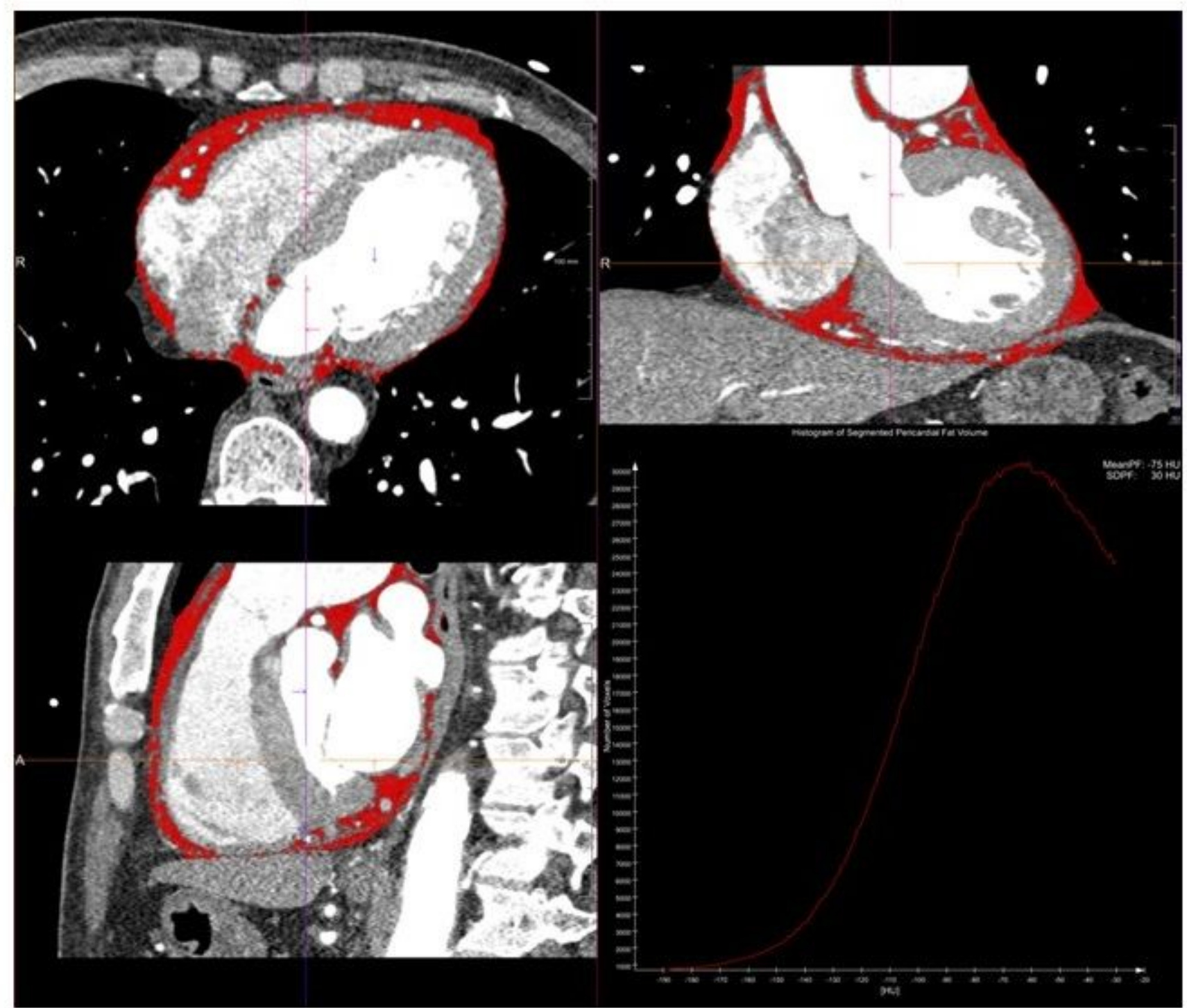

Figure 1

Epicardial adipose tissue (EAT) quantification. Measurement of EAT volume and radiodensity by automated software. EAT is highlighted in red. 


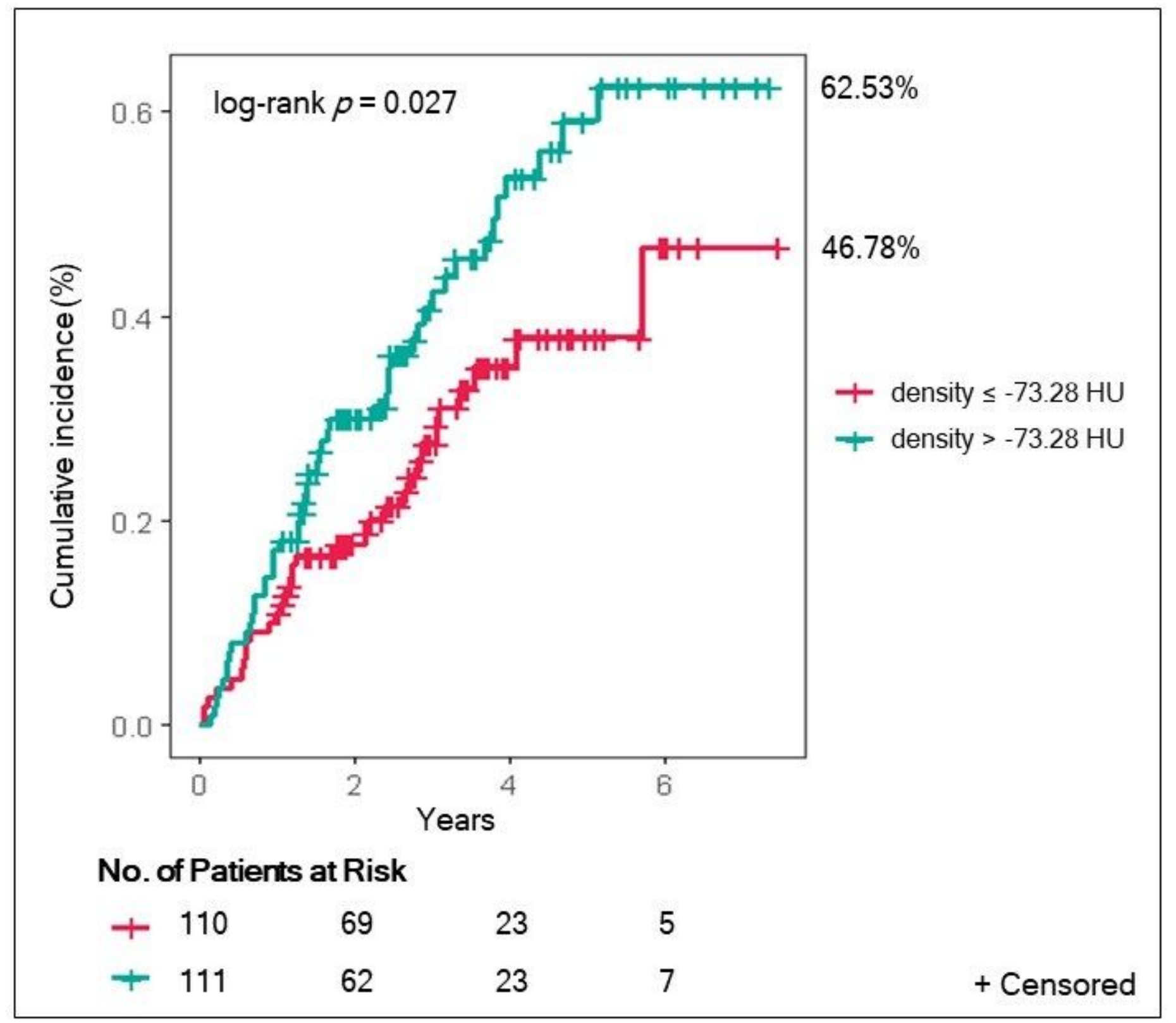

Figure 2

Comparison of the risks factors for all-cause mortality between the high and low EAT radiodensity groups. EAT, epicardial adipose tissue; HU, Hounsfield unit.

\section{Supplementary Files}

This is a list of supplementary files associated with this preprint. Click to download.

- SupplementalMaterials.pdf 